\title{
Calciphylaxis: a severe complication of renal disease
}

\section{Nina Scola MD, Alexander Kreuter MD}

Competing interests: None declared.

This article has been peer reviewed.

\section{Affiliations:}

From the Department of Dermatology, Venereology and Allergology, Ruhr University, Bochum, Germany

\section{Correspondence to:}

Dr. Nina Scola, n.scola@klinikum -bochum.de

CMAJ 2011. DOI:10.1503 /cmaj.110046

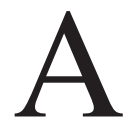
n 82-year-old man with end-stage renal disease, who had been receiving hemodialysis for five years, presented with a three-month history of erythematous patches on his legs. Clinical examination showed multiple painful cutaneous ulcerations coated with dark eschar, surrounded by indurated, violaceous plaques (Figure 1). An important laboratory finding was a markedly elevated phosphate concentration (1.95 [normal 0.87-1.45] mmol/L), associated with normal concentrations of calcium and parathyroid hormone. Histopathologic evaluation showed intramural deposition of calcium in several subcutaneous arterioles (Appendix 1, available at www.cmaj.ca/lookup/suppl/doi:10.1503 /cmaj.110046/-/DC1). Radiologic examination showed calcification of the large arteries of the leg (Appendix 2, available at www.cmaj.ca/lookup /suppl/doi:10.1503/cmaj.110046/-/DC1). Calciphylaxis was diagnosed. Surgical débridement was performed, and the patient was given culturedirected intravenous antibiotic therapy, resulting in an improvement in the skin lesions. However, his general condition worsened, and he eventually died of septicemia.

Calciphylaxis, also known as calcific uremic arteriolopathy, is a microvascular occlusion syndrome with mural calcification of arterioles leading to severe ischemia of the tissue. It occurs in up to $4 \%$ of patients undergoing long-term dialysis, but sporadic instances in patients with normal renal function have also been reported. ${ }^{1,2}$ In addition to kidney failure, other risk factors include obesity, female sex, white race, liver disease, use of systemic corticosteroids, decreased albumin levels and elevated calcium-phosphorus products. ${ }^{2,3}$ Parathyroid hormone is often found to be abnormal. Mortality associated with calciphylaxis is high, with an estimated one-year rate of survival of $45 \%$. $^{3}$

The pathogenesis of calciphylaxis may be linked to an imbalance of homeostasis in the bones. ${ }^{3}$ Excisional biopsy should be done to confirm the diagnosis. The main differential diagnoses include pyoderma gangrenosum, coagulopathies and arteriosclerotic ulcers. Although

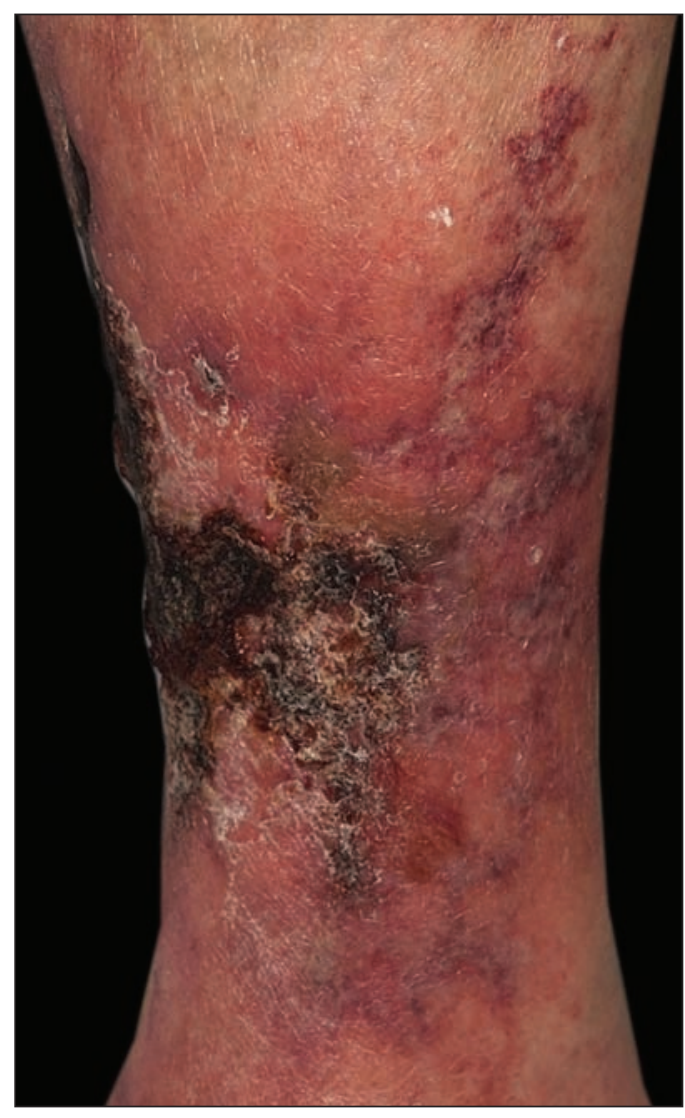

Figure 1: Leg of an 82-year-old man with end-stage renal disease showing ulceration with thick eschar, surrounded by indurated, violaceous, retiform plaques.

there are no guidelines on therapy, treatment usually consists of surgical débridement of necrotic lesions of the skin and identification and correction of the underlying metabolic disturbances. ${ }^{3}$ Promising results have been reported after treatment with cinacalcet and sodium thiosulfate. ${ }^{2}$

\section{References}

1. Angelis M, Wong LL, Myers SA, et al. Calciphylaxis in patients on haemodialysis: a prevalence study. Surgery 1997;122:1083-9.

2. Kalajian AH, Malhotra PS, Callen JP, et al. Calciphylaxis with normal renal and parathyroid function: not as rare as previously believed. Arch Dermatol 2009;145:451-8.

3. Weenig RH, Sewell LD, Davis MD, et al. Calciphylaxis: natural history, risk factor analysis, and outcome. J Am Acad Dermatol 2007;56:569-79. 